\title{
Heart rate and blood pressure is associated with renal function in patients with type 1 diabetes in the absence of nephropathy and therapeutical interventions
}

\author{
Tomislav Bulum ${ }^{1,2}$, Hrvoje Premec', Lea Duvnjak, \\ ${ }^{1}$ Merkur University Hospital, Vuk Vrhovac Clinic for Diabetes, Endocrinology and Metabolic Diseases, Zagreb, Croatia \\ ${ }^{2}$ The University of Zagreb, School of Medicine, Zagreb, Croatia
}

\begin{abstract}
Background. Albuminuria, heart rate (HR) and blood pressure are established predictors of chronic kidney disease and cardiovascular disease. The objective of this study was to explore the relationship between HR, systolic blood pressure (SBP) and diastolic blood pressure (DBP) with renal function parameters in patients with type 1 diabetes (T1DM) without therapeutical interventions.

Material and methods. Study included 313 normoalbuminuric T1DM. HR was determined using a standard 12-lead ECG and blood pressure with a mercury sphygmomanometer, both after a resting period of 10 minutes. Urinary albumin excretion rate (UAE) was measured from at least two 24-h urine samples. Data on serum creatinine levels, age, sex and race were used to calculate the estimated glomerular filtration rate (eGFR) using the Chronic Kidney Disease Epidemiology Collaboration (CKD-EPI) formula.

Results. eGFR was significantly associated with duration of diabetes, $\mathrm{HbA}_{\mathrm{lc}}$, LDL-cholesterol, and HDL-cholesterol (for the duration of diabetes $r=-0.29, p<0.001$ ). UAE significantly correlated with duration of diabetes, HDL-cholesterol, triglycerides, HR and DBP (for HR and DBP $r=0.21-0.23, p<0.001$ ). Subjects in the $4^{\text {th }}$ quartile of UAE had significantly higher HR rate compared to subjects in $1^{\text {st }}, 2^{\text {nd }}$, and $3^{\text {rd }}$ quartiles $(70 \pm 11 v$ s. $74 \pm 12$ vs. $74 \pm 12$ vs. $79 \pm 13$ beats/min, $\mathrm{p}=0.001$ ).
\end{abstract}

Conclusions. Results of our study suggest that interplay between $\mathrm{HR}$ with renal function parameters is present even in T1DM with normal renal function.

Key words: type 1 diabetes; heart rate; renal function; albuminuria

Arterial Hypertens. 2019, vol. 23, no. 1, pages: 30-34

DOI: 10.5603/AH.a2019.0001

Address for correspondence: Tomislav Bulum, MD, PhD

Vuk Vrhovac Clinic for Diabetes, Endocrinology and Metabolic Diseases, University Hospital Merkur, Medical School, University of Zagreb, Croatia Dugi dol 4a, 10000 Zagreb, Croatia, tel: (+38) 512353 991, fax: (+38) 512331480

e-mail: tbulum@idb.hr

VM Copyright $(2019$ Via Medica, ISSN 2449-6170 


\section{Introduction}

Diabetes mellitus is the most common cause of chronic kidney disease in the world [1]. Patients with diabetes, in order to prevent development or progression of renal disease, need strict control of risk factors, which includes not only good glycemic control but also optimal lipid and blood pressure control [2]. Heart rate (HR) is an easily measurable biological parameter for which determination simple instruments are required. HR is generally considered to be an unreliable biological marker in epidemiological studies because it depends on the methods and conditions under which it is measured and it is also often underestimated in the clinical setting [3]. Although the HR has its clear limitations, there are studies that clearly showed the association between resting HR and the chronic kidney disease in patients with type 1 and type 2 diabetes. Schmieder et al. [4] and Hillis et al. [5] connected elevated resting HR with an increased risk of microalbuminuria in patients with type 2 diabetes, while Choe et al. [6] connected elevated resting HR in adolescents with elevated albuminuria. Moreover, there is an evident association between resting HR and mortality in patients with hypertension, coronary heart disease and patients with left ventricular systolic dysfunction [7-10].

In addition to HR, elevated systolic blood pressure (SBP) and diastolic blood pressure (DBP) are associated with the development of chronic kidney disease and with increased mortality in patients with and without diabetes [11, 12]. Moreover, elevated blood pressure, as well as its oscillations, are with diabetes the most important cause of the development and progression of chronic kidney disease [13, 14]. On the other hand, the development of chronic kidney disease in patients with diabetes highly increases the risk of developing cardiovascular diseases and mortality [15].

The risk of development of microalbuminuria can be predicted by changes in urinary albumin excretion (UAE), which is still within the physiological range [16]. Microalbuminuria is considered to be the earliest stage of renal disease in patients with diabetes and the therapeutic approach is based on providing a therapy that will prevent the development and progression of microalbuminuria. Recently published 5-year retrospective analysis showed a $21 \%$ cumulative incidence of chronic kidney disease in a large cohort of patients with type 1 diabetes mellitus (T1DM) with preserved kidney function at baseline and with nearly $4 \%$ of patients developing renal impairment and 18\% developing albuminuria
[17]. The aim of this study was to explore the relationship between HR and blood pressure with renal function parameters in T1DM without therapeutical interventions.

\section{Material and methods}

This study included 313 patients with type 1 diabetes defined according to the age of diagnosis (below 35 years), autoantibodies positivity and insulin treatment initiated within 1 year of diagnosis. The study included patients with minimum duration of diabetes of 1 year and age between 18-65 years. We excluded from the study patients that were treated with antihypertensive therapy and lipid-lowering therapy. We also excluded from the study patients with acute and chronic inflammation.

Basic anthropometric measurements were performed on all study subjects. HR was determined using a standard 12-lead ECG and blood pressure with a mercury sphygmomanometer, both after a resting period of 10 minutes. Urinary albumin excretion rate (UAE) was determined as the mean of 24-h urine collections measured from at least two 24-h urine samples. We excluded from the study patients with microalbuminuria (UAE $\geq 30<300 \mathrm{mg} / 24 \mathrm{~h}$ ), macroalbuminuria (UAE $\geq 300 \mathrm{mg} / 24 \mathrm{~h}$ ) and those with estimated glomerular filtration rate (eGFR) less than $60 \mathrm{ml} \mathrm{min}^{-1} 1.73 \mathrm{~m}^{-2}$ calculated using the Chronic Kidney Disease Epidemiology Collaboration (CKD-EPI) formula [18, 19].

Hemoglobin $\mathrm{A}_{1 \mathrm{c}}\left(\mathrm{HbA}_{1 \mathrm{c}}\right)$ and serum lipids were determined in all patients after an overnight fast. Microalbumin and $\mathrm{HbA}_{\mathrm{lc}}$ were measured spectrophotometrically by turbidimetric immuno-inhibition (Olympus AU600, Beckman-Coulter, USA). Serum lipids were measured by an enzymatic colourimetric method.

Data are expressed as means \pm SD for normally distributed values, as median with range for nonnormally distributed values, and percentage. Pearson's correlation coefficients were used to calculate correlations between normally distributed values and Spearman's rank correlation coefficients were used for non-normally distributed values. To investigate the relationship between $\mathrm{HR}$ and blood pressure with renal function parameters data were also stratified in quartiles depending on UAE as well as in different groups of eGFR. Kruskal-Wallis test was used for calculating the significance of the trend for each variable among the different groups. Level of statistical significance was chosen to be $\alpha=0.05$. Statistical analysis was performed by statistical package STATA/IC ver.11.1. 


\section{Results}

The characteristics of the study subjects are listed in Table I. Mean/median values of BMI, HDL-cholesterol, triglycerides, serum creatinine, UAE, eGFR, HR as well as blood pressure were within the normal range for patients with diabetes, with slightly elevated HbAlc and LDL-cholesterol levels. Correlations between renal function parameters and HR, blood pressure and metabolic parameters are presented in Table II. eGFR was significantly associated with duration of diabetes, $\mathrm{HbA}_{1 c}$, LDL-cholesterol, and HDL-cholesterol, with duration of diabetes showing the strongest correlation $(r=-0.29, \mathrm{p}<0.001)$. UAE was significantly associated with duration of diabetes, HDL-cholesterol, triglycerides, HR and DBP, with $\mathrm{HR}$ and $\mathrm{DBP}$ showing the strongest correlation $(\mathrm{r}=0.21-0.23, \mathrm{p}<0.001)$.

Table I. Clinical and metabolic characteristics of all patients

\begin{tabular}{|l|c|}
\hline Variable & Value \\
\hline Age (years) & $34(18-65)$ \\
Duration of diabetes (years) & $12(1-42)$ \\
$\mathrm{BMI}\left[\mathrm{kg} / \mathrm{m}^{2}\right]$ & $24(15-37)$ \\
$\mathrm{HbA}_{1 \mathrm{c}}(\%)$ & $7.43 \pm 1.63$ \\
$\mathrm{SBP}[\mathrm{mm} \mathrm{Hg}]$ & $120(79-180)$ \\
$\mathrm{DBP}[\mathrm{mm} \mathrm{Hg}]$ & $80(50-100)$ \\
Heart rate $($ beats/min) & $74 \pm 13$ \\
LDL cholesterol $[\mathrm{mmol} / \mathrm{L}]$ & $2.8 \pm 0.7$ \\
$\mathrm{HDL}$ cholesterol $[\mathrm{mmol} / \mathrm{L}]$ & $1.7 \pm 0.4$ \\
Triglycerides $[\mathrm{mmol} / \mathrm{L}]$ & $0.91(0.3-4.1)$ \\
Serum creatinine $[\mu \mathrm{mol} / \mathrm{L}]$ & $71 \pm 14$ \\
eGFR $\left[\mathrm{mL} \mathrm{min}{ }^{-1} 1.73 \mathrm{~m}^{-2}\right]$ & $106 \pm 16$ \\
UAE $[\mathrm{mg} / 24 \mathrm{~h}]$ & $11.0(1.7-29.8)$ \\
\hline
\end{tabular}

$\mathrm{BMI}$ - body mass index: $\mathrm{HbA}_{1}$ — hemoglobin $\mathrm{A} \cdot \mathrm{SBP}$ — systolic blood pressure; DBP — diastolic blood pressure; $L D L$ - low density lipoprotein; $H D L$ - high density lipoprotein; eGFR — estimated glomerular filtration rate; UAE - urinary albumin excretion
The relationship between blood pressure and HR among those in the $2^{\text {nd }}, 3^{\text {rd }}$ and $4^{\text {th }}$ quartiles of UAE compared to those in quartile 1 are presented in Table III. Stratifying blood pressure and HR for the degree of UAE, trends across quartiles of UAE for HR was statistically significant $(\mathrm{p}=0.001)$. Subjects in the $4^{\text {th }}$ quartile of UAE had significantly higher HR compared to subjects in $1^{\text {st }}, 2^{\text {nd }}$, and $3^{\text {rd }}$ quartiles. We also explore the relationship between blood pressure and HR according to the level of eGFR. Stratifying blood pressure and HR for the degree of eGFR, trends were not statistically significant for HR and blood pressure (Tab. IV).

\section{Discussion}

This cross-sectional study investigated the causal relationship between renal function parameters and

Table II. Correlation analysis of associations of renal function parameters with heart rate, blood pressure and metabolic parameters

\begin{tabular}{|l|c|c|}
\hline Variable & UAE & eGFR \\
\hline Duration of diabetes & $0.14^{*}$ & $-0.29^{*}$ \\
BMI & -0.02 & -0.10 \\
HBA $_{1 c}$ & 0.07 & $0.15^{*}$ \\
LDL cholesterol & 0.03 & $-0.18^{*}$ \\
HDL cholesterol & $-0.13^{*}$ & $-0.17^{*}$ \\
Triglycerides & $0.11^{*}$ & 0.06 \\
SBP & 0.09 & -0.08 \\
DBP & $0.23^{*}$ & -0.01 \\
Heart rate & $0.21^{*}$ & 0.21 \\
\hline
\end{tabular}

UAE — urinary albumin excretion rate; GFR — estimated glomerular filtration rate; $\mathrm{BMI}$ - body mass index; $\mathrm{HbA}_{1 \mathrm{c}}$ - haemoglobin $\mathrm{A}_{1 \mathrm{cc}}$ LDL — low density lipoprotein; $\mathrm{HDL}$ — high density lipoprotein; SBP — systolic blood pressure; DBP — diastolic blood pressure; ${ }^{*} p<0.05$

Table III. Quartiles of urinary albumin excretion rate

\begin{tabular}{|l|c|c|c|c|c|}
\hline & $\begin{array}{c}1^{\text {st }} \text { quartile } \\
(<6.8 \mathrm{mg} / \mathbf{2 4} \mathrm{h})\end{array}$ & $\begin{array}{c}2^{\text {nd }} \text { quartile } \\
(\geq \mathbf{6 . 8}<\mathbf{1 1 . 0})\end{array}$ & $\begin{array}{c}3^{\text {rd }} \text { quartile } \\
(\geq \mathbf{1 1 . 0}<\mathbf{1 6 . 7})\end{array}$ & $\begin{array}{c}4^{\text {th }} \text { quartile } \\
(\geq \mathbf{1 6 . 7} \mathbf{~ m g} / \mathbf{2 4} \mathrm{h})\end{array}$ & $\begin{array}{c}\mathbf{p} \\
\text { for trend }\end{array}$ \\
\hline Heart rate (beats/min) & $70 \pm 11$ & $74 \pm 12$ & $74 \pm 12$ & $79 \pm 13$ & 0.001 \\
\hline $\mathrm{SBP}[\mathrm{mm} \mathrm{Hg}]$ & $120(90-145)$ & $120(90-180)$ & $120(90-170)$ & $120(80-180)$ & 0.19 \\
\hline DBP $[\mathrm{mm} \mathrm{Hg}]$ & $80(60-90)$ & $80(60-90)$ & $80(60-110)$ & $80(50-110)$ & 0.1 \\
\hline
\end{tabular}

SBP — systolic blood pressure; DBP — diastolic blood pressure

Table IV. Blood pressure and heart rate depending on the level of estimated glomerular filtration rate

\begin{tabular}{|l|c|c|c|c|}
\hline \multirow{2}{*}{ Variable } & \multicolumn{3}{|c|}{ eGFR [mL min $\left.^{-1} \mathbf{1 . 7 3} \mathbf{~ m}^{-2}\right]$} & \multirow{2}{*}{$p$} \\
\cline { 2 - 4 } & $>\mathbf{6 0} \leq \mathbf{9 0}$ & $>\mathbf{9 0} \leq \mathbf{1 2 5}$ & $>125$ & \\
\hline Heart rate (beats/min) & $74 \pm 12$ & $73 \pm 12$ & $78 \pm 16$ & 0.3 \\
\hline SBP $[\mathrm{mm} \mathrm{Hg}]$ & $120(80-170)$ & $120(90-180)$ & $120(90-140)$ & 0.7 \\
\hline DBP $[\mathrm{mm} \mathrm{Hg}]$ & $80(65-10)$ & $80(60-110)$ & $80(50-90)$ & 0.1 \\
\hline
\end{tabular}

SBP — systolic blood pressure; DBP — diastolic blood pressure 
blood pressure and HR in T1DM who were not taking any other therapy (antilipidemic or antihypertensive) except insulin. In correlation analysis, the strongest correlations were recorded between HR, DBP and UAE. Moreover, after stratifying blood pressure and HR for the degree of UAE, trends across quartiles of UAE for HR was statistically significant $(\mathrm{p}=0.001)$ in our patients with normoalbuminuria.

All our studied patients have normal renal function according to eGFR and albuminuria. However, it is increasingly being examined whether there is a safe level of albumin excretion in the urine. Several studies showed that in non-diabetic patients as well as in those with diabetes, a higher normal UAE predicts the development of cardiovascular and renal adverse events [20,21]. Consequently, there is a growing prevalence of an opinion that the UAE should be observed as a continuous variable [22]. Our study cannot conclude about the causal relationship between high normal UAE and future renal impairment, but it does show that subgroups of different UAE, which may be correlated with different parameters, exist within the group of normoalbuminuric T1DM. In addition, in normoalbuminuric type 2 diabetic patients, the UAE is correlated with many factors that are potentially susceptible to intervention [23].

Heart Rate is a strong and independent predictor of major cardiovascular complications including myocardial infarction, heart failure, cardiac death, and stroke and also with all-cause mortality in subjects with and without diabetes $[24,25]$. It is also documented that higher HR is associated with increased prevalence and severity of microalbuminuria and that HR and microalbuminuria were each independently associated with the composite endpoint of all-cause death, myocardial infarction, and stroke $[26,27]$. Histological studies in humans showed that the renal endings of sympathetic fibres are not only in contact with the kidney vasculature, but also with renal tubules and juxtaglomerular cells, while animal models showed that these neural endings are involved in hemodynamic regulation, tubular transport, and renin secretion [28, 29]. Increased sympathetic activity in humans have a deleterious effect on renal function, regardless of the accompanying hypertension [30]. The highest influence of the sympathetic nervous system is precisely on the podocytes. Although adrenergic fibers do not reach to glomerulus [31], podocytes possess adrenergic receptors [32]. Adrenergic receptors on podocytes mediate calcium influx in the podocytes, causing their contraction and decreasing their selective bandwidth [32]. It is suggested that these possible mechanisms of increased sympathetic activity are associated with higher UAE. It is well known that the resting HR is determined by the activity of the sinus node and that resting HR may serve as an indicator of sympathetic hyperactivity or insufficient vagal activity [33]. In our study, there is no information whether the increased sympathetic activity precedes increased UAE in the normal range or whether there is an inverse relationship of causality, but results clearly shows that there are signs of increased sympathetic activity in the group of patients with higher UAE. However, it has been shown that cardiac autonomic neuropathy is an independent risk factor for cardiovascular morbidity and mortality in T1DM with nephropathy, but not in those without nephropathy with normoalbuminuria [34].

The present study has a number of potential limitations. First, our study was not prospective which limited our ability to infer a causal relation between $\mathrm{HR}$, blood pressure and renal function parameters. Second, ambulatory blood pressure measurement is more useful than causal or office blood pressure measurement [35]. Lastly, our analyses were based on a single measurement of $\mathrm{HR}$, blood pressure and albuminuria that may not reflect the relation over time.

In conclusion, the results of our study suggest that interplay between blood pressure and HR with renal function parameters are present even in T1DM with normal renal function. The most obvious explanation is that higher HR indicates autonomic dysfunction and sympathetic nerve activation, which are associated with increased albuminuria. Whether the detection of elevated resting HR in normoalbuminuric T1DM has predictive value for the development of albuminuria and nephropathy needs to be assessed in further follow-up studies.

\section{Conflict of interest}

The authors disclose no conflict of interest.

\section{Ethical approval}

All procedures were in accordance with the ethical standards of the institutional committee and with the 1964 Helsinki declaration and its later amendments or comparable ethical standards.

\section{References}

1. Steigerwalt S. Management of Hypertension in Diabetic Patients With Chronic Kidney Disease. Diabetes Spectrum. 2008; 21(1): 30-36, doi: 10.2337/diaspect.21.1.30.

2. American Diabetes Association. 10. Microvascular Complications and Foot Care: Standards of Medical Care in Diabetes 2018. Diabetes Care. 2018; 41(Suppl 1): S105-S118, doi: 10.2337/dc18-S010, indexed in Pubmed: 29222381. 
3. Inoue $\mathrm{T}$, Iseki $\mathrm{K}$, Iseki $\mathrm{C}$, et al. Heart rate as a risk factor for developing chronic kidney disease: longitudinal analysis of a screened cohort. Clin Exp Nephrol. 2009; 13(5): 487-493, doi: 10.1007/ s10157-009-0193-3, indexed in Pubmed: 19444548.

4. Schmieder RE, Bramlage P, Haller H, et al. ROADMAP Investigators. The effect of resting heart rate on the new onset of microalbuminuria in patients with type 2 diabetes: a subanalysis of the ROADMAP study. Medicine (Baltimore). 2016; 95(15): e3122, doi: 10.1097/ MD.0000000000003122, indexed in Pubmed: 27082551.

5. Hillis GS, Hata J, Woodward M, et al. Resting heart rate and the risk of microvascular complications in patients with type 2 diabetes mellitus. J Am Heart Assoc. 2012; 1(5): e002832, doi: 10.1161/ JAHA.112.002832, indexed in Pubmed: 23316296.

6. Cho YHi, Craig ME, Davis EA, et al. Adolescent Type 1 Diabetes Cardio-Renal Intervention Trial. Cardiac autonomic dysfunction is associated with high-risk albumin-to-creatinine ratio in young adolescents with type 1 diabetes in AdDIT (adolescent type 1 diabetes cardio-renal interventional trial). Diabetes Care. 2015; 38(4): 676-681, doi: 10.2337/dc14-1848, indexed in Pubmed: 25573882.

7. Gillman MW, Kannel WB, Belanger A, et al. Influence of heart rate on mortality among persons with hypertension: the Framingham Study. Am Heart J. 1993; 125(4): 1148-1154, indexed in Pubmed: 8465742 .

8. Paul L, Hastie CE, Li WS, et al. Resting heart rate pattern during follow-up and mortality in hypertensive patients. Hypertension. 2010; 55(2): 567-574, doi: 10.1161/HYPERTENSIONAHA.109.144808, indexed in Pubmed: 20038750.

9. Diaz A, Bourassa MG, Guertin MC, et al. Long-term prognostic value of resting heart rate in patients with suspected or proven coronary artery disease. Eur Heart J. 2005; 26(10): 967-974, doi: 10.1093/ eurheartj/ehi190, indexed in Pubmed: 15774493.

10. Fox K, Ford I, Steg PG, et al. BEAUTIFUL investigators. Heart rate as a prognostic risk factor in patients with coronary artery disease and left-ventricular systolic dysfunction (BEAUTIFUL): a subgroup analysis of a randomised controlled trial. Lancet. 2008; 372(9641): 817-821, doi: 10.1016/S0140-6736(08)61171-X, indexed in Pubmed: 18757091.

11. Levey AS, Astor BC, Stevens LA, et al. Chronic kidney disease, diabetes, and hypertension: what's in a name? Kidney Int. 2010; 78(1): 19-22, doi: 10.1038/ki.2010.115, indexed in Pubmed: 20428101.

12. Stojceva-Taneva O, Selim G, Stojkovski L, et al. Hypertension and progression of nephropathy in diabetic and non-diabetic chronic kidney disease patients. Hippokratia. 2007; 11(2): 72-76, indexed in Pubmed: 19582181.

13. Di Iorio B, Pota A, Sirico ML, et al. Blood pressure variability and outcomes in chronic kidney disease. Nephrol Dial Transplant. 2012; 27(12): 4404-4410, doi: 10.1093/ndt/gfs328, indexed in Pubmed: 22962409.

14. Ravera M, Re M, Deferrari L, et al. Importance of blood pressure control in chronic kidney disease. J Am Soc Nephrol. 2006; 17(4 Suppl 2): S98-103, doi: 10.1681/ASN.2005121319, indexed in Pubmed: 16565257.

15. Pálsson R, Patel UD. Cardiovascular complications of diabetic kidney disease. Adv Chronic Kidney Dis. 2014; 21(3): 273-280, doi: 10.1053/j.ackd.2014.03.003, indexed in Pubmed: 24780455.

16. Dunger DB, Schwarze CP, Cooper JD, et al. Can we identify adolescents at high risk for nephropathy before the development of microalbuminuria? Diabet Med. 2007; 24(2): 131-136, doi: 10.1111/j.1464-5491.2006.02047.x, indexed in Pubmed: 17257274.

17. Piscitelli P, Viazzi F, Fioretto P, et al. Predictors of chronic kidney disease in type 1 diabetes: a longitudinal study from the AMD Annals initiative. Sci Rep. 2017; 7(1): 3313, doi: 10.1038/s41598-01703551-w, indexed in Pubmed: 28607417.

18. Levey AS, Stevens LA, Schmid CH, et al. CKD-EPI (Chronic Kidney Disease Epidemiology Collaboration). A new equation to estimate glomerular filtration rate. Ann Intern Med. 2009; 150(9): 604-612, indexed in Pubmed: 19414839.
19. Vučić Lovrenčić M, Radišić Biljak V, Božičević S, et al. Estimating glomerular filtration rate (GFR) in diabetes: the performance of MDRD and CKD-EPI equations in patients with various degrees of albuminuria. Clin Biochem. 2012; 45(18): 16941696, doi: 10.1016/j.clinbiochem.2012.07.115, indexed in Pubmed: 22968085.

20. Wachtell K, Ibsen H, Olsen $\mathrm{MH}$, et al. Albuminuria and cardiovascular risk in hypertensive patients with left ventricular hypertrophy: the LIFE study. Ann Intern Med. 2003; 139(11): 901-906, indexed in Pubmed: 14644892.

21. Rachmani R, Levi Z, Lidar M, et al. Considerations about the threshold value of microalbuminuria in patients with diabetes mellitus: lessons from an 8-year follow-up study of 599 patients. Diabetes Res Clin Pract. 2000; 49(2-3): 187-194, indexed in Pubmed: 10963831.

22. Ruggenenti P, Remuzzi G. Time to abandon microalbuminuria? Kidney Int. 2006; 70(7): 1214-1222, doi: 10.1038/sj.ki.5001729, indexed in Pubmed: 16871239.

23. Ritz E, Viberti GC, Ruilope LM, et al. Determinants of urinary albumin excretion within the normal range in patients with type 2 diabetes: the Randomised Olmesartan and Diabetes Microalbuminuria Prevention (ROADMAP) study. Diabetologia. 2010; 53(1): 49-57, doi: 10.1007/s00125-009-1577-3, indexed in Pubmed: 19876613.

24. Fox KM. Current status: heart rate as a treatable risk factor. European Heart Journal Supplements. 2011; 13(Suppl C): C30-C36, doi: 10.1093/eurheartj/sur016.

25. Hillis GS, Woodward M, Rodgers A, et al. Resting heart rate and the risk of death and cardiovascular complications in patients with type 2 diabetes mellitus. Diabetologia. 2012; 55(5): 1283-1290, doi: 10.1007/s00125-012-2471-y, indexed in Pubmed: 22286552.

26. Böhm M, Reil JC, Danchin N, et al. Association of heart rate with microalbuminuria in cardiovascular risk patients: data from I-SEARCH. J Hypertens. 2008; 26(1): 18-25, doi: 10.1097 / HJH.0b013e3282f05c8a, indexed in Pubmed: 18090536.

27. Pfister R, Erdmann E, Schneider CA. Association and prognostic impact of heart rate and micro- albuminuria in patients with type 2 diabetes and cardiovascular disease: results from the PROactive trial. J Atheroscler Thromb. 2011; 18(1): 65-71, indexed in Pubmed: 21088369.

28. DiBona GF. Physiology in perspective: The Wisdom of the Body. Neural control of the kidney. Am J Physiol Regul Integr Comp Physiol. 2005; 289(3): R633-R641, doi: 10.1152/ajpregu.00258.2005, indexed in Pubmed: 16105818.

29. Koomans HA, Blankestijn PJ, Joles JA. Sympathetic hyperactivity in chronic renal failure: a wake-up call. J Am Soc Nephrol. 2004; 15(3): 524-537, indexed in Pubmed: 14978154.

30. Joles JA, Koomans HA. Causes and consequences of increased sympathetic activity in renal disease. Hypertension. 2004; 43(4): 699-706, doi: 10.1161/01.HYP.0000121881.77212.b1, indexed in Pubmed: 14981063.

31. Johns EJ, Kopp UC, DiBona GF, et al. Neural control of renal function. Physiol Rev. 1997; 77(1): 75-197, doi: 10.1152/physrev.1997.77.1.75, indexed in Pubmed: 9016301.

32. Pavenstädt H, Kriz W, Kretzler M. Cell biology of the glomerular podocyte. Physiol Rev. 2003; 83(1): 253-307, doi: 10.1152/physrev.00020.2002, indexed in Pubmed: 12506131.

33. Menown IBA, Davies S, Gupta S, et al. Resting heart rate and outcomes in patients with cardiovascular disease: where do we currently stand? Cardiovasc Ther. 2013; 31(4): 215-223, doi: 10.1111/j.17555922.2012.00321.x, indexed in Pubmed: 22954325.

34. Astrup AS, Tarnow L, Rossing P, et al. Cardiac autonomic neuropathy predicts cardiovascular morbidity and mortality in type 1 diabetic patients with diabetic nephropathy. Diabetes Care. 2006; 29(2): 334-339, indexed in Pubmed: 16443883.

35. Mancia G, Parati G. Ambulatory blood pressure monitoring and organ damage. Hypertension. 2000; 36(5): 894-900, indexed in Pubmed: 11082163. 